\title{
In-system photoelectron spectroscopy study of tin oxide layers produced from tetrakis(dimethylamino)tin by plasma enhanced atomic layer deposition.
}

Running title: In-system XPS study of PEALD $\mathrm{SnO}_{2}$

Running Authors: G.Chistiakova et al.

\section{Ganna Chistiakova ${ }^{a}$, Mathias Mews}

Institute for Silicon Photovoltaics, Helmholtz-Zentrum Berlin für Materialien und Energie GmbH, Kekuléstraße 5, D-12489 Berlin, Germany

\section{Regan G. Wilks, Marcus Bär}

Energy Materials In-Situ Laboratory Berlin (EMIL) Helmholtz-Zentrum Berlin für Materialien und Energie GmbH, Albert-Einstein-Str. 15, D-12489 Berlin, Germany

\section{Lars Korte}

Institute for Silicon Photovoltaics, Helmholtz-Zentrum Berlin für Materialien und Energie GmbH, Kekuléstraße 5, D-12489 Berlin, Germany

\section{a) Electronic mail: ganna.chistiakova@helmholtz-berlin.de}

Tin oxide $\left(\mathrm{SnO}_{2}\right)$ layers were deposited using plasma enhanced atomic layer deposition with tetrakis(dimethylamino)tin precursor and oxygen plasma. Deposited layers were analyzed by spectral ellipsometry, conductivity measurements, and in-system photoelectron spectroscopy. Within a deposition temperature range of $90-210^{\circ} \mathrm{C}$, the resistivity of the $\mathrm{SnO}_{2}$ layers decreases by five orders of magnitude with increasing deposition temperature. At the same time, the refractive index at $632.8 \mathrm{~nm}$ increases from 1.7 to 1.9. These changes in bulk layer properties are connected to results from photoelectron spectroscopy. It is found that decreasing carbon and nitrogen contaminations in the tin oxide layers lead to decreasing optical band gap and increasing refractive index. Additionally, for the deposited $\mathrm{SnO}_{2}$ layers a shoulder in the $\mathrm{O} 1 \mathrm{~s}$ core level spectrum is observed that decreases with deposition temperature and thus is proposed to be related to hydroxyl groups. 


\section{INTRODUCTION}

Tin oxide $\left(\mathrm{SnO}_{2}\right)$ is a transparent wide-band gap n-type semiconductor that is used for a variety of different applications, such as sensors ${ }^{1}$, lithium-ion batteries ${ }^{2}$, oxidation catalysts ${ }^{3}$ and photovoltaics ${ }^{4}$. In photovoltaics, the most common usage of $\mathrm{SnO}_{2}$ is in an alloy with $\mathrm{InO}_{\mathrm{x}}$ to form indium-tin-oxide (ITO) ${ }^{5}$, or doped with additives e.g. fluorine, which yields fluorinetin-oxide (FTO) ${ }^{6}$, which are used in solar cells as transparent conductive oxides (TCOs) and anti-reflection layers. $\mathrm{SnO}_{2}$ on its own is not as conductive as other TCOs like ITO, FTO or aluminum doped zinc oxide $(\mathrm{AZO})^{7}$. However, with the further development of perovskite solar cells, the usage of pure $\mathrm{SnO}_{2}$ has recently become more prominent, due to its high transparency and the suitable energy alignment between $\mathrm{SnO}_{2}$ and perovskites ${ }^{8}$. Therefore, $\mathrm{SnO}_{2}$ can be used as an electron transport layer in perovskite solar cells ${ }^{8-11}$, or in tandem devices like perovskite-silicon heterojunction solar cells ${ }^{12,13}$.

Since perovskite and silicon heterojunction solar cells both feature layers, which are susceptible to degradation at elevated temperatures, it is mandatory for the solar cell applications to deposit $\mathrm{SnO}_{2}$ below $200^{\circ} \mathrm{C}^{14}$. Due to the high reactivity of the oxygen plasma $^{15}$, plasma enhanced atomic layer deposition (PEALD) with an appropriate precursor can allow these low deposition temperatures. Usage of a highly reactive plasma might damage the functional layers underneath, as was shown for PEALD of $\mathrm{MoO}_{\mathrm{x}}$ in silicon heterojunction cells. ${ }^{16}$ However, it is possible to almost fully recover the electronic properties of the layer after an annealing step at $190-200{ }^{\circ} \mathrm{C} .{ }^{17}$ Furthermore, the plasma-induced damage can be reduced by tuning the plasma parameters, such as plasma power, or gas pressure. ${ }^{18}$

For our $\mathrm{SnO}_{2}$ layers TetrakisdimethylaminoTin (TDMASn) was chose as a suitable precursor, because of its high reactivity and suitable temperature window $<250{ }^{\circ} \mathrm{C}$, with a decomposition temperature at 250-300 ${ }^{\circ} \mathrm{C}^{19,20}$. PEALD of $\mathrm{SnO}_{2}$ with TDMASn was successfully applied to solar cells ${ }^{10-13}$, but so far the optical and electrical properties of these layers were not investigated in detail.

The purpose of this work is to investigate the optical and electrical properties of PEAL deposited $\mathrm{SnO}_{2}$ layers, and to relate these properties to the chemical information gathered from in-system photoelectron spectroscopy.

\section{EXPERIMENTAL}




\section{A. Substrate preparation}

For XPS measurements c-Si (100) wafers coated with a $10 \mathrm{~nm}$ intrinsic a-Si:H film layer were used as substrates. They were prepared as follows: c-Si wafers (n-type, resistivity $\sim 2-5 \Omega \mathrm{cm}$ ) were cleaned with the standard RCA process ${ }^{21}$ and dipped in $1 \% \mathrm{HF}$ solution for 2 minutes in order to remove the native oxide. The samples were then introduced into a PECVD-ALD-cluster tool, and a-Si:H layers were grown by plasma-enhanced chemical vapor deposition (PECVD) from silane $\left(\mathrm{SiH}_{4}\right)$ and hydrogen at a sample temperature of $200{ }^{\circ} \mathrm{C}$. Samples were then moved to the ALD chamber without breaking the vacuum.

For the electrical and optical measurements, Corning glass substrates were used. Prior to the ALD process, they were cleaned with Mucasol universal detergent.

\section{B. Atomic layer deposition and optimization of the cycle}

The $\mathrm{SnO}_{2}$ films were grown by PEALD at $90-210^{\circ} \mathrm{C}$ using an oxygen plasma, produced by a remote plasma source (RPS) with an oxygen flow of $100 \mathrm{sccm}$. The Sn precursor for $\mathrm{SnO}_{2}$ layers was TDMASn (Sigma Aldrich 99.99\% purity), which was held in a stainless steel canister at room temperature. The precursor feed-in was realized using an injector held at $60{ }^{\circ} \mathrm{C}$ and helium as carrier gas. The line temperature was sustained at $90{ }^{\circ} \mathrm{C}$ to prevent condensation of the precursor in the line. $100 \mathrm{sccm}$ of $\mathrm{N}_{2}$ was used as a purge gas. Additionally, an $\mathrm{N}_{2}$ flow of $8 \mathrm{sccm}$ was necessary to sustain a uniform temperature of the ceramic heater in the chamber.

Each PEALD sequence consisted of a TDMASn pulse (1.5 s)- $\mathrm{N}_{2}$ purge (5 s)-Oxygen plasma pulse (varied duration)- $\mathrm{N}_{2}$ purge $(5 \mathrm{~s})$. During the process the pressure was set by a pressure control valve and was kept at 0.5 mbar throughout the whole process.

TDMASn and $\mathrm{N}_{2}$ pulses were optimized to yield saturation of the film growth per cycle (GPC). However, for PEALD the saturation point for the plasma step cannot be adjusted in the same way as for thermal ALD mostly due to plasma kinetics. If the reaction kinetic is slow and plasma species are distributed isotropically ${ }^{22,23}$, it is possible to obtain better quality layers before the saturation point. Therefore, the parameters of the oxidation step (pulse time, plasma power) were optimized with regard to conductivity of the $\mathrm{SnO}_{2}$ layer. Moreover, for further improvement of the plasma's reactivity an additional flow of $10 \mathrm{sccm}$ argon was introduced into the chamber during the oxidation step. The initial (not optimized) cycle had the oxygen step duration of 2 seconds, with RPS power of $150 \mathrm{~W}$. After the optimization, the optimum oxygen step duration was established at 6 seconds, at an RPS power of $300 \mathrm{~W}$. For longer durations or higher plasma power density, there is a possibility of plasma-induced 
defects inside the material, or at the surface $e^{23}$ and increase of energetic radical concentration that could remove reactive sites from the substrate ${ }^{24}$. More detailed information on cycle optimization is provided in the supplementary material. Additionally, for the investigation of byproducts influence with XPS, the dataset for the plasma duration optimization was used. The parameters for this dataset are: deposition temperature of $120^{\circ} \mathrm{C}$, RPS power $300 \mathrm{~W}$, and the oxygen duration time 2-8 seconds.

All deposited $\mathrm{SnO}_{2}$ layers had thicknesses in the range of 20-30 nm after 200 ALD cycles, as derived from ellipsometry measurements.

\section{Film characterization}

During the PEALD, GPC was estimated by fitting in-situ ellipsometry data with the Drude model. Final samples were analyzed with external spectroscopic ellipsometry, employing a Sentech ellipsometer SE 850, in a wavelength range of 190-850 nm, using the Tauc-Lorentz model, in order to obtain the final thicknesses, band gaps, and refractive indices of the $\mathrm{SnO}_{2}$ layers.

After PEALD, samples were directly transferred to the XPS chamber via ultra-high vacuum (UHV) with base pressure in the range of $5 \times 10^{-10} \mathrm{mbar}$. The highest pressure (caused by rapid movement of the UHV transfer mechanisms and the opening/closing of valves) the samples were exposed to during the transfer is $10^{-7}$ mbar. XPS measurements were done using a ScientaOmicron Argus CU electron analyzer employing non-monochromatized $\mathrm{Mg} \mathrm{K}_{\alpha}$ excitation. Analysis of the XPS elemental core level spectra was done using the software fityk $^{25}$. The spectra were fit simultaneously using Voigt profiles with coupled Gaussian and Lorentzian line widths including a linear background. The change in elemental composition of the studied layers was compared by means of comparing the peak areas after subtraction of the fitted background relative to the total area of the main peaks (i.e., carbon, nitrogen, oxygen, and the $3 \mathrm{~d}_{3 / 2}$ contribution of the $\mathrm{Sn} 3 \mathrm{~d}$ doublet).

Dark conductivity measurements to derive the electrical properties were performed using a mercury probe at room temperature ${ }^{26}$.

\section{Results and discussion}

\section{A. Optical and electrical properties of $\mathrm{SnO}_{2}$ as a function of deposition temperature}

In the following, we compare temperature variation series for two sets of process parameters: an initial (not optimized) process ( $2 \mathrm{~s}, 150 \mathrm{~W}$ oxygen plasma step) and an optimized process (6 s, $300 \mathrm{~W}$ oxygen plasma step with $10 \mathrm{sccm}$ of additional Ar flow). 


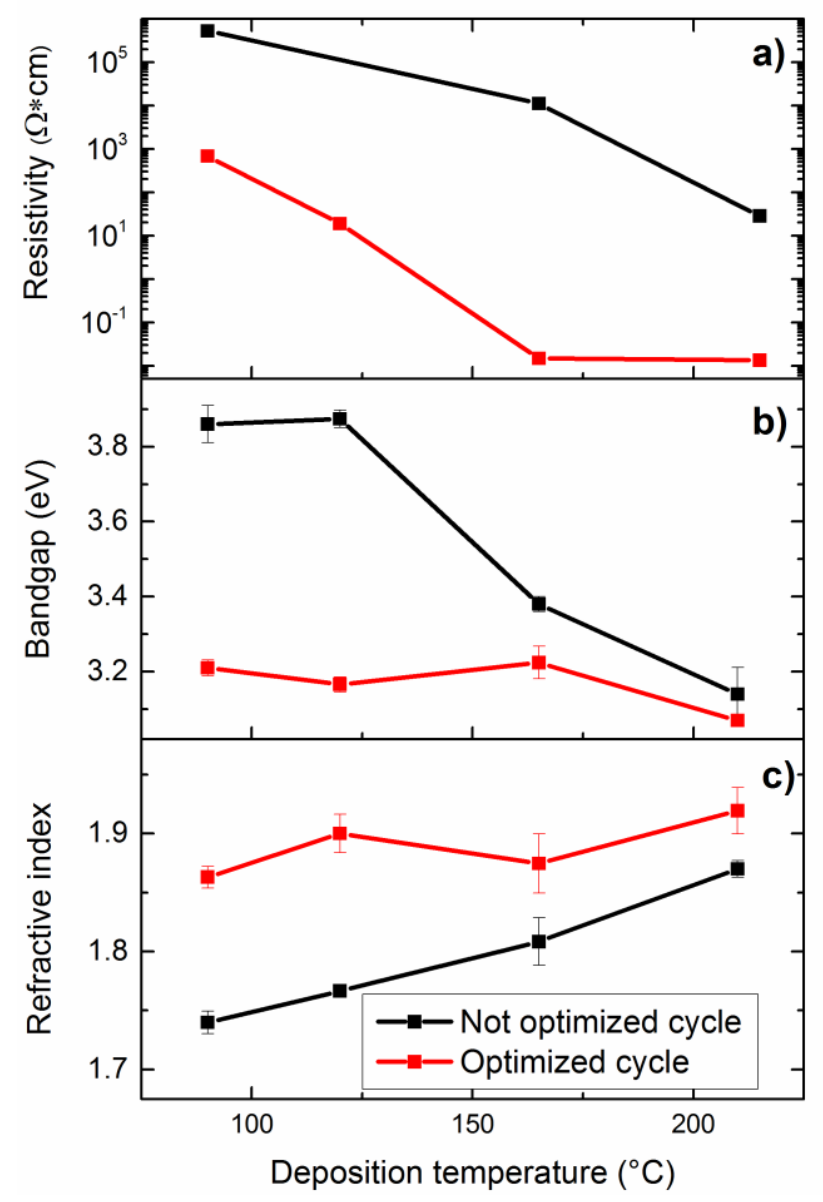

FIG. 1. (Color online) (a) Resistivity, (b) optical band gap and (c) refractive index at $632.8 \mathrm{~nm}$ for $\mathrm{SnO}_{2}$ layers deposited using both the not optimized and optimized cycle parameters, as a function of deposition temperature.

For these two parameter sets, Fig. 1. shows a variation of electrical and optical properties of the deposited $\mathrm{SnO}_{2}$ layers as a function of the deposition temperature. For the electrical properties, as shown in Fig. 1(a) both trends show similar behavior over temperature, with a drastic decrease of resistivity by about 4-5 orders of magnitude when changing the deposition temperature from $120^{\circ} \mathrm{C}$ to $200^{\circ} \mathrm{C}$. The resistivity of samples deposited using the optimized cycle saturates at about $10 \mathrm{~m} \Omega \mathrm{cm}$ at a deposition temperature of $165^{\circ} \mathrm{C}$, while the resistivity of samples deposited with the not optimized process is more than three orders of magnitude higher. At low deposition temperatures this resistivity even increased to $\sim 10^{5} \Omega \mathrm{cm}$, i.e. the detection limit of the used measurement setup. Thus, for the sample of the not optimized process deposited at $120{ }^{\circ} \mathrm{C}$, no resistivity could be measured. For the optimized cycle, the $\mathrm{SnO}_{2}$ layers show similar conductivities and a comparable trend vs. deposition temperature as reported for thermal ALD using the same precursor ${ }^{19,20}$. 
The optical properties, as presented in Fig.1 (b,c), follow the same general trend for both cycles, but both changes in band gap and refractive index are more prominent for the non-optimized cycle samples. For the high deposition temperatures it is possible to achieve refractive index values of 1.9, which is in the acceptable range for high-quality $\mathrm{SnO}_{2}$ thin films ${ }^{19}$.

\section{B. XPS analysis of layers}

All $\mathrm{SnO}_{2}$ layers were deposited in the range of $90-210^{\circ} \mathrm{C}$. It was shown in literature before that layers produced with TDMASn at deposition temperatures below $250^{\circ} \mathrm{C}$ have an amorphous structure ${ }^{19,20,27}$. Therefore, we can assume that the most likely reason for the drastic change in optical and electrical layer properties with deposition temperature is a change of the deposited layer's composition. XPS measurements were conducted to further investigate whether precursor remainders and/or byproducts are present/incorporated at the surface or in the volume of the $\mathrm{SnO}_{2}$ films.

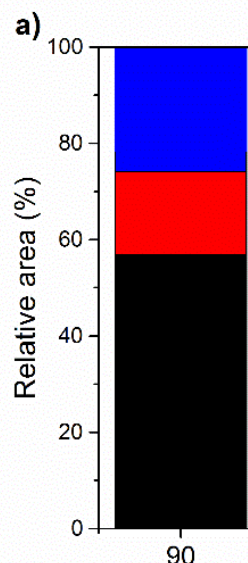

90

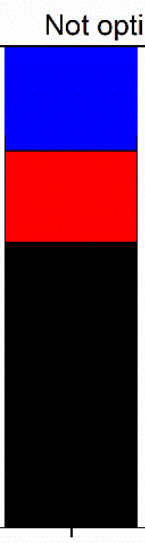

120

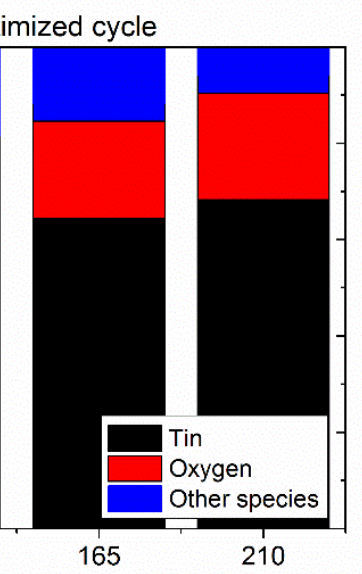

Deposition temperature $\left({ }^{\circ} \mathrm{C}\right)$

b)

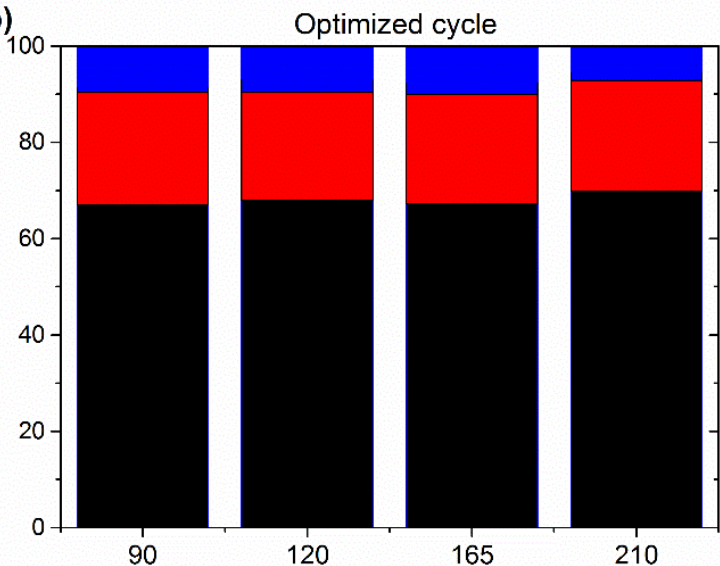

FIG. 2. (Color online) Relative XPS peak areas of core levels in PEALD $\mathrm{SnO}_{2}$ layers as a function of deposition temperature for (a) not optimized and (b) optimized cycle parameters.

The XPS data analyzed for these $\mathrm{SnO}_{2}$ layers include tin $3 \mathrm{~d}_{3 / 2}$, oxygen $1 \mathrm{~s}$, carbon $1 \mathrm{~s}$ and nitrogen 1s signals. Details regarding the peak fitting of all XPS data from $\mathrm{SnO}_{2}$ layers with different deposition conditions are presented in the supplementary material. Before discussing the core level spectra in more detail below, we present an overview of the findings: Fig. 2 shows the relative peak areas of core levels that are present in the $\mathrm{SnO}_{2}$ for both processes ("not optimized" and "optimized"). For this plot, we label the total peak area of Sn $3 \mathrm{~d}_{3 / 2}$ core level spectrum as "tin", the area of the main peak in the O 1s spectra (see discussion related to Fig. 7, below) as "oxygen", and the sum of the area of the $\mathrm{C} 1 \mathrm{~s}, \mathrm{~N} 1 \mathrm{~s}$, and $\mathrm{O} 1 \mathrm{~s}$ 
secondary peak as "other species" (see discussion below for more details). For both the optimized and the non-optimized sets of deposition parameters, with increase of the temperature there is a decrease of "other species", which include nitrogen, carbon residuals and -OH groups. This decrease is more prominent for the not optimized cycle parameters, where the relative area of "other species" at the lowest temperature was above $20 \%$. Note that the relative area of "other species" at low temperatures for the optimized cycle is almost comparable with the area for high temperatures using the non-optimized cycle. However, the trend with temperature change is similar in both the optimized and non-optimized sets of samples.

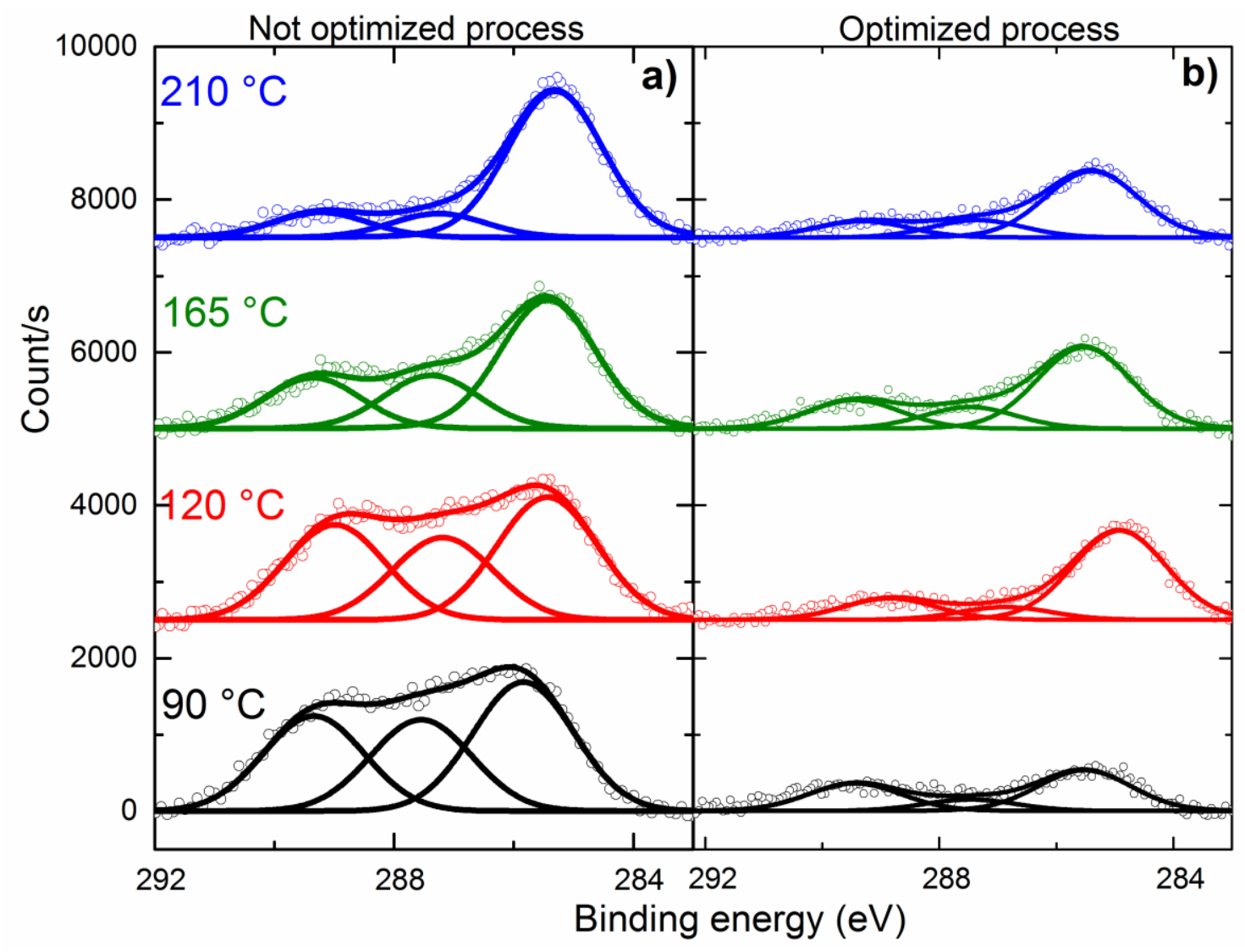

FIG. 3. (Color online) C 1s XPS spectra of the $\mathrm{SnO}_{2}$ films deposited at different temperatures (a) for not optimized and (b) optimized process. The spectra (data: open circles; fit: solid lines) are shown after subtraction of the fitted linear background and are offset for better visibility.

We proceed by discussing the carbon $\mathrm{C} 1 \mathrm{~s}$ and nitrogen $\mathrm{N}$ 1s core levels. In Fig. 3 the carbon $\mathrm{C}$ 1s spectra of $\mathrm{SnO}_{2}$ layers deposited at different temperatures are shown. Three peaks are sufficient to fit these spectra, with binding energies centered around 285.2-285.5 eV, 287$287.3 \mathrm{eV}$ and 289.2-289.5 eV. The peak with the highest binding energy at about $289.4 \mathrm{eV}$ can be attributed to $\mathrm{O}=\mathrm{C}-\mathrm{N}$ bonds ${ }^{28}$, or other carboxyl containing precursor residues. The 
peak at about $287 \mathrm{eV}$ can be attributed to carbon-nitrogen bonds of ethyl groups as present in the form of $\mathrm{N}-\mathrm{CH}_{2}-\mathrm{CH}_{3}$ residues from the TDMASn precursor. Unlike these two peaks, the third one, which has the lowest binding energy, does not show any clear correlation with changing deposition temperature, and is attributed to carbon atoms bond to hydrogen ${ }^{29}$. (See Suppl. Table 1 for a detailed list of relevant chemical environments of carbon and their respective $\mathrm{C} 1 \mathrm{~s}$ binding energies.) The two peaks in the $\mathrm{C} 1 \mathrm{~s}$ signal, that are assumed to be due to precursor remainders, show a clear decrease of peak area with increasing deposition temperature.

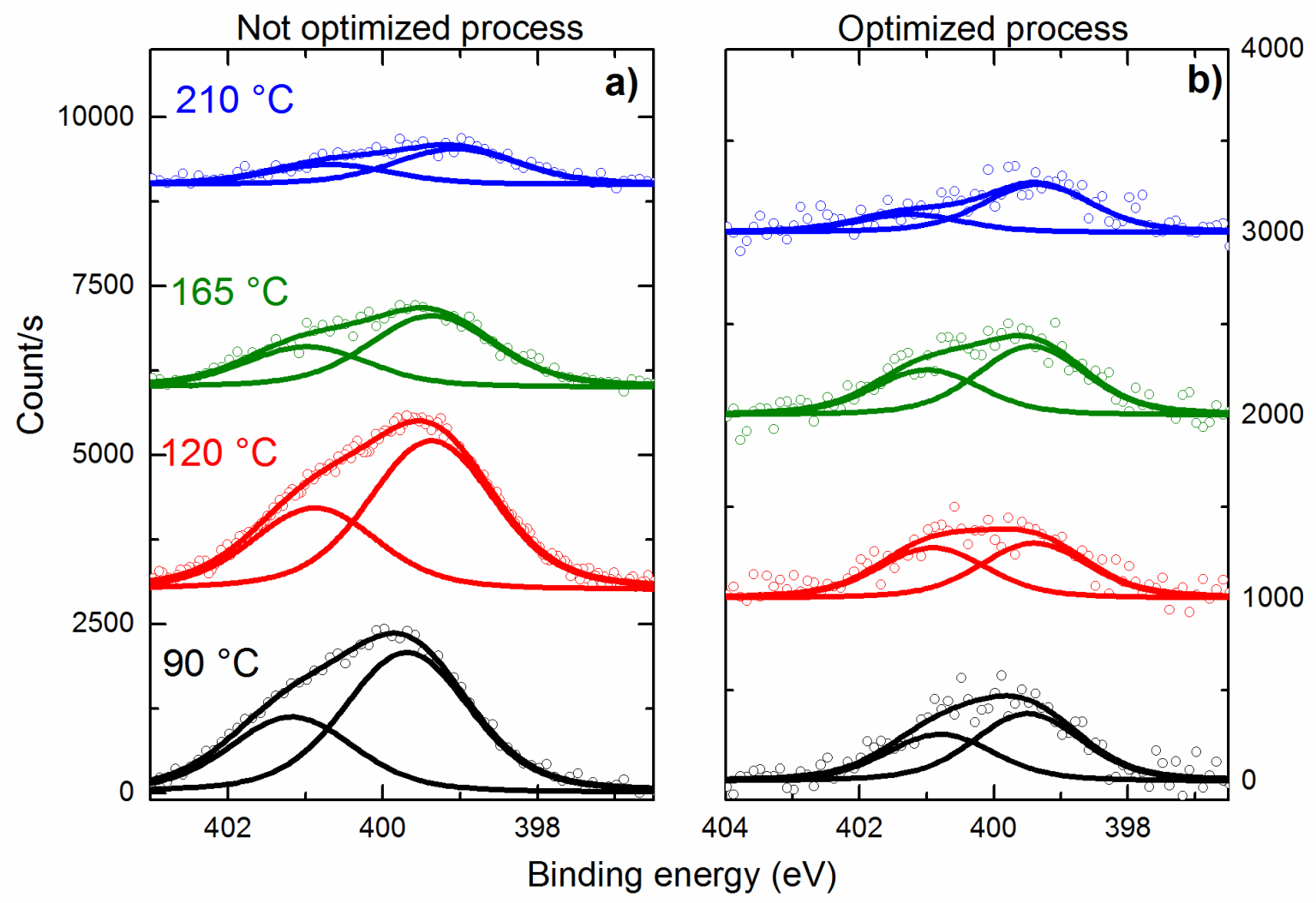

FIG. 4. (Color online) N 1s XPS spectra of the $\mathrm{SnO}_{2}$ films deposited at different temperatures (a) for not optimized and (b) optimized process. The spectra (data: open circles; fit: solid lines) are shown after subtraction of the fitted linear background and are offset for better visibility.

After evaluating the $\mathrm{C} 1 \mathrm{~s}$ signal, we turn our attention to the $\mathrm{N}$ 1s core level. Similar to the carbon signal, there is a clear correlation between the overall peak area and deposition temperature, as it is shown in Fig 4. The spectrum was fitted with two peaks, where the signal at lower binding energy of $399.2-399.5 \mathrm{eV}$ is assumed to originate from the $\mathrm{N}-\mathrm{CH}_{2}-\mathrm{CH}_{3}$ TDMASn precursor ${ }^{29}$ residues, and the higher energy part at energies $401.5-401.8 \mathrm{eV}$ from $\mathrm{O}=\mathrm{C}-\mathrm{N}$ related bonds, as concluded from Fig. $3 .{ }^{28}$ 


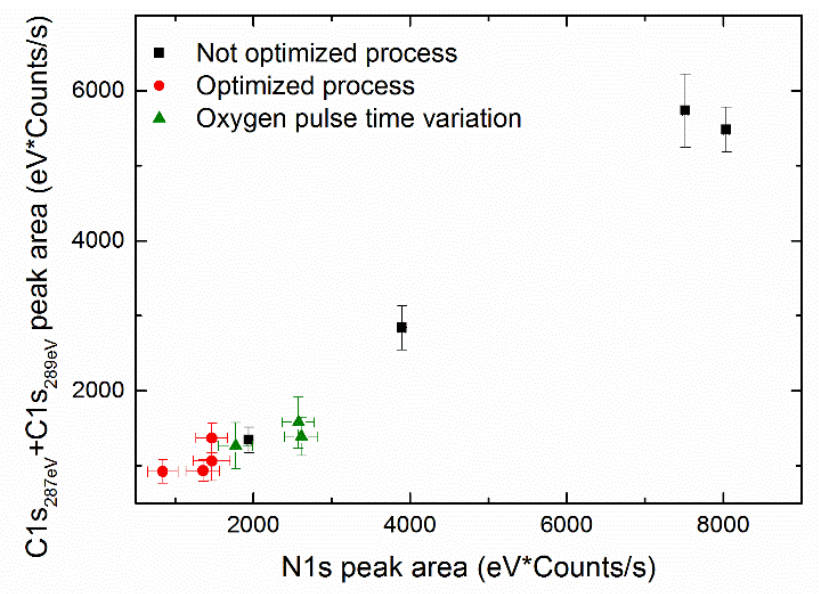

FIG.5. (Color online) Sum of peak areas of the 287-287.3 eV ("C1 $1 \mathrm{~s}_{287 \mathrm{eV}}$ ") and the 289.2-289.5 eV ("C1s $289 \mathrm{ev")} \mathrm{contribution} \mathrm{to} \mathrm{the} \mathrm{C} \mathrm{1s} \mathrm{core} \mathrm{level} \mathrm{plotted} \mathrm{versus} \mathrm{the} \mathrm{total} \mathrm{area} \mathrm{of}$ the N 1s signal. Data points represent samples from the three studied sample sets: "not optimized process" (oxygen pulse time: $2 \mathrm{~s}$, RPS power $150 \mathrm{~W}$, deposition temperature: 90$210^{\circ} \mathrm{C}$ ), “optimized process" (oxygen pulse time: $6 \mathrm{~s}$, RPS power $300 \mathrm{~W}$, deposition temperature: $90-210^{\circ} \mathrm{C}$ ), and "oxygen pulse time variation" at $120^{\circ} \mathrm{C}$.

In Fig. 5, the area sum of the $\mathrm{C} 1 \mathrm{~s}$ contributions that are proposed to be due to precursor remainders is plotted against the total area of the $\mathrm{N}$ 1s peak for different deposition conditions. Clearly, with increasing nitrogen $\mathrm{N}$ 1s area, there is also an area increase of the two high-binding energy $\mathrm{C}$ 1s signals. This shows that these two groups of signals are directly related to each other. Therefore, it is likely that these signals are indeed caused by TDMASn residuals incorporated in the $\mathrm{SnO}_{2}$ layers and that these remainders contain nitrogen-carbon bonds. Since the intensities of these signals decrease with increasing deposition temperature, it can be surmised that with increasing deposition temperature less precursor residues are incorporated into the layer due to more efficient precursor decomposition.

However, even at the highest investigated temperatures and for the optimized cycle, there is a noticeable amount of carbon and nitrogen contamination. In contrast, for $\mathrm{SnO}_{2}$ layers deposited with TDMASn and thermal ALD, at deposition temperatures above $200^{\circ} \mathrm{C}$ other authors have found no nitrogen or carbon in their films ${ }^{19,20,30,31}$. It can be concluded that for PEALD deposition incorporation of impurities from the precursor cannot be prevented even at elevated deposition temperatures. Therefore, it is important to understand how the contamination from the precursor affects the optical and electrical characteristics of the deposited films. To this end samples with different deposition conditions were investigated to clarify the influence of the contaminations on the layers properties. 


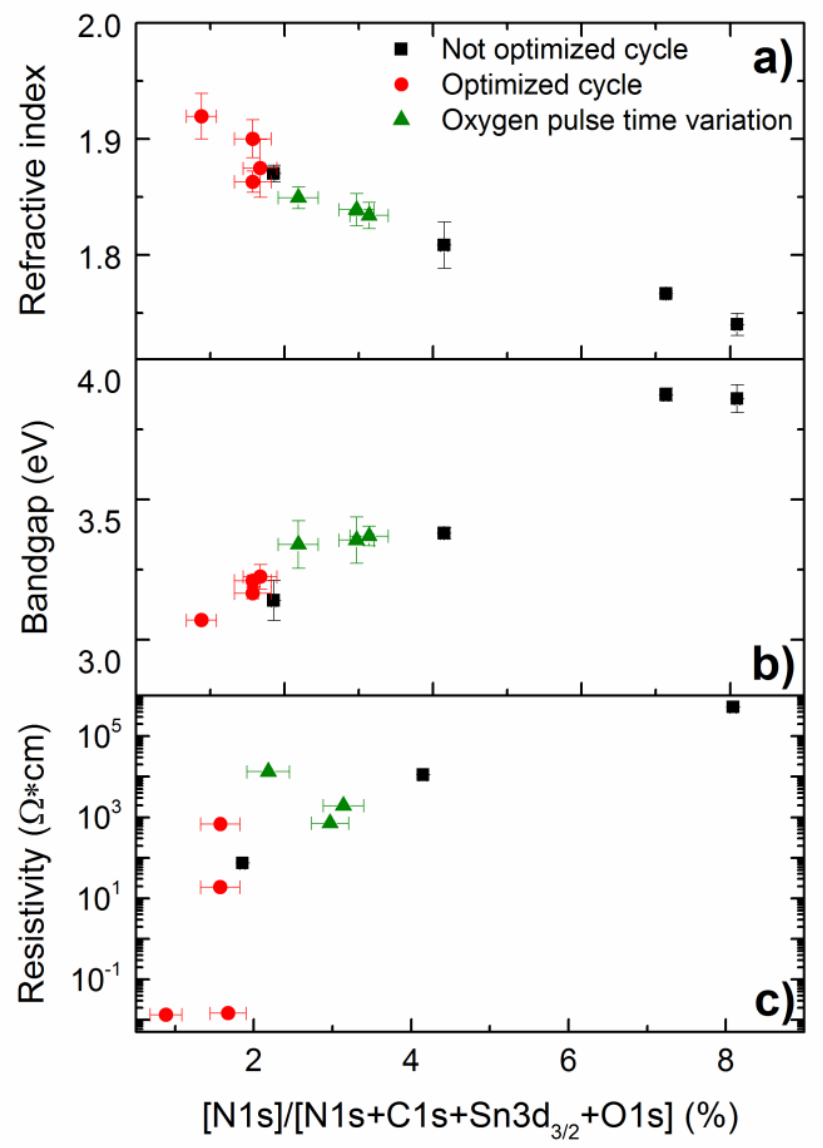

FIG.6. (Color online) (a) refractive index at $632.8 \mathrm{~nm}$, (b) optical band gap and (c) layer resistivity of $\mathrm{SnO}_{2}$ as a function of relative area of the $\mathrm{N}$ 1s signal. Data points represent samples from the three studied sample sets: "not optimized process" (oxygen pulse time: $2 \mathrm{~s}$, RPS power $150 \mathrm{~W}$, deposition temperature: 90-210 ${ }^{\circ} \mathrm{C}$ ), “optimized process" (oxygen pulse time: $6 \mathrm{~s}$, RPS power $300 \mathrm{~W}$, deposition temperature: $90-210^{\circ} \mathrm{C}$ ), and "oxygen pulse time variation" at $120^{\circ} \mathrm{C}$.

Fig.6 (a,b) shows the optical properties of the $\mathrm{SnO}_{2}$ layers vs. the relative nitrogen $1 \mathrm{~s}$ peak area. It is seen that the refractive index and the optical band gap depend strongly on the content of nitrogen-containing residues from the precursor. Additionally, the highest refractive index along with a minimal band gap is achieved for the lowest amount of precursor residuals in the layer. Several explanations are possible for the observed increase of the bandgap with the increase of the residues in the layer: in highly degenerately doped semiconductors an increase of the optical band gap is observed, since the optical excitation has to overcome the distance between the valence band and Fermi-level, instead of valence band to conduction band. This so-called Burstein-Moss shift is caused by a large density of free charge carriers (generally resulting in a low resistivity) and has previously been observed, 
e.g. for $\mathrm{Sb}$ and $\mathrm{F}$ doped $\mathrm{SnO}_{2}{ }^{32}$ However, in our case, as it is seen from Fig. 6 (b,c) the optical band gap increases with increasing resistivity, which contradicts a Burstein-Moss effect.

Another more probable explanation is that residue bonded $\mathrm{Sn}$ atoms lead to electronic states within in the band edges and that these states replace states in the band tails, which would otherwise contribute to an increased optical absorption and seemingly lower optical band gap. Similar behavior has been reported for other amorphous materials e.g. amorphous silicon $^{33}$. We assume that this can be explained by a dehydroxylation of tin oxide, as it will be discussed in the next section.

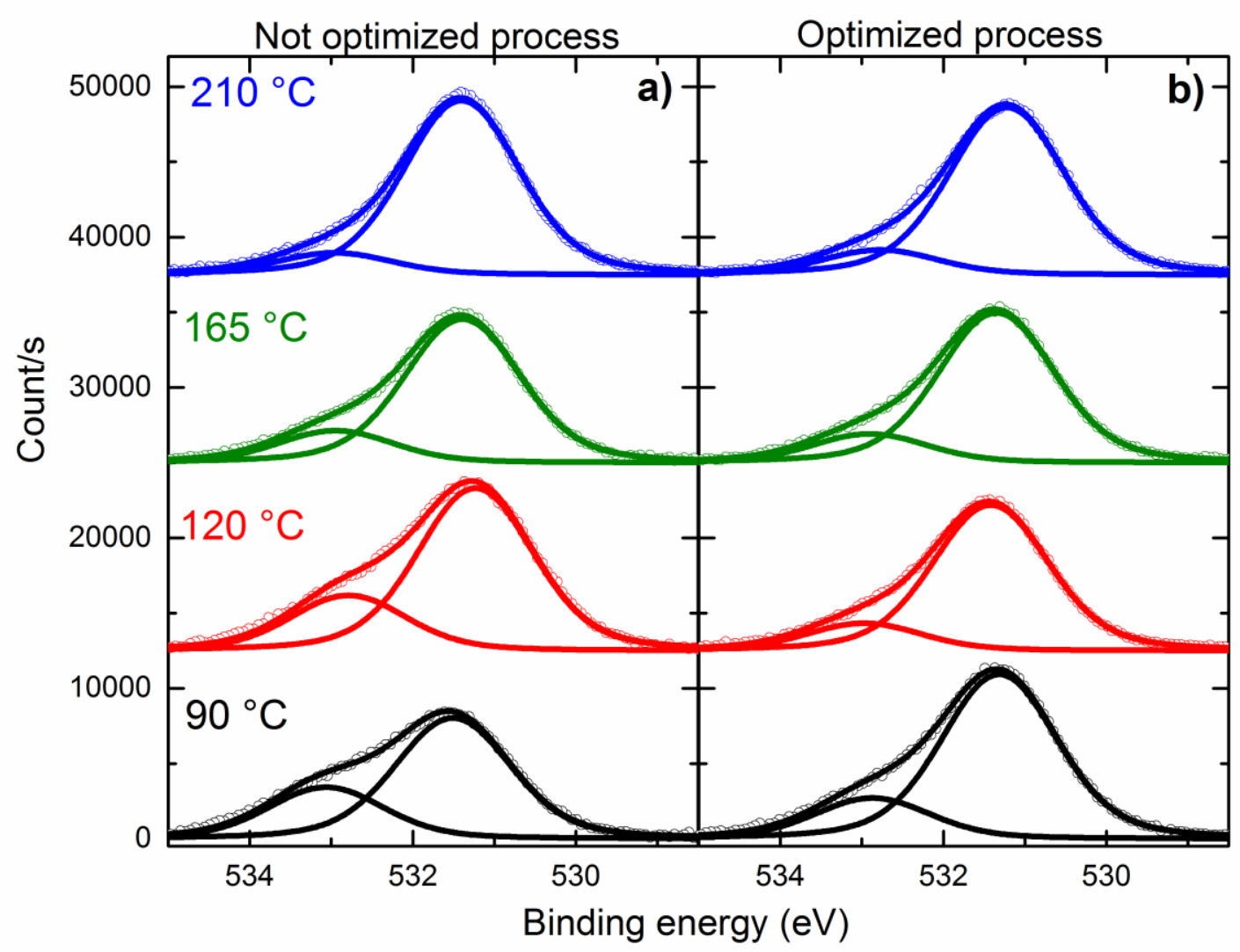

FIG.7. (Color online) O 1s XPS spectra of the $\mathrm{SnO}_{2}$ films deposited at different temperatures (a) for not optimized and (b) optimized process. The spectra (data: open circles; fit: solid lines) are shown after subtraction of the fitted linear background and are offset for better visibility.

Nitrogen and carbon signals are not the only signals that show a dependence on deposition temperature. It is visible from Fig 7 that the O 1s XPS signal also undergoes drastic changes upon deposition temperature variation. The $\mathrm{O} 1 \mathrm{~s}$ signal was fitted with two components: the main peak centered at 531.2-531.4 eV corresponds to O-Sn bonds ${ }^{34}$, and the 
secondary signal centered at 532.7-533.3eV, which corresponds to other oxygen species, like $-\mathrm{OH}$ groups or carboxides ${ }^{35,36}$. However, it is not possible to discriminate between the $-\mathrm{OH}$ groups and carboxides in these spectra, since their binding energies have a significant overlap. (See also Suppl. Table 2 for a more complete list of relevant chemical environments of oxygen and their respective $\mathrm{O} 1 \mathrm{~s}$ binding energies). However, it can be observed that with increasing temperature the $\mathrm{O}-\mathrm{Sn}$ related signal intensity remains almost constant, while the impurity related signal intensity decreases with increasing temperature. Assuming that the high-binding energy contribution to the $\mathrm{O} 1$ s signal indeed is attributed to $-\mathrm{OH}$ groups, a possible explanation for its temperature induced decrease is the dehydroxylation with increasing temperature ${ }^{37}$. Therefore, the density of - $\mathrm{OH}$ groups at the surface of the film decreases. However, it is known for PEALD of $\mathrm{Al}_{2} \mathrm{O}_{3}$ that $-\mathrm{OH}$ groups can be located not only at the surface, but also incorporated into the layer ${ }^{22,38}$. Thus, it can be assumed that the incorporation of hydroxyl groups in the layer may also happen during $\mathrm{SnO}_{2}$ PEALD. Additionally, since the samples deposited using the optimized cycle show lower $\mathrm{OH}$ signals and lower band gaps, than the samples deposited using the not optimized cycle, it can be concluded that the dehydroxylation of the layer leads to a decreased band gap.

\section{IV.Summary and conclusion}

Layer properties of $\mathrm{SnO}_{2}$ deposited using TDMASn precursor and an oxygen plasma in the deposition temperature range of $90-210^{\circ} \mathrm{C}$ were investigated. The PEALD cycle optimization for this process was discussed, and three sets of layers were investigated in detail: One set of samples is based on the initial not optimized process, the other on the final optimized process. For the third additional sample set the oxygen pulse time was varied. The influence of deposition parameters on optical and electrical properties was investigated, and XPS measurements were conducted to connect these macroscopic layer properties with the layer composition.

It was shown that in all layers deposited with PEALD, residual carbon and nitrogen are present that can be assigned to the remainders from not fully reacted precursor molecules. These contaminations, which decrease with deposition temperature, have a direct influence on the refractive index and optical band gap of $\mathrm{SnO}_{2}$ layers. Additionally, a shoulder in the $\mathrm{O} 1 \mathrm{~s}$ core level spectrum is indicative of $-\mathrm{OH}$ groups and/or carboxide groups present in the film, or at its surface. It was shown that with increasing deposition temperature, there is a decrease of this high-binding energy $\mathrm{O} 1 \mathrm{~s}$ signal. Assuming that the majority of this signal can indeed be attributed to -OH groups, its thermally induced decrease could be interpreted as a dehydroxylation of the $\mathrm{SnO}_{2}$ layers. 
Moreover, the influence of deposition temperature on the electrical properties of $\mathrm{SnO}_{2}$ layers was investigated. The layer resistivity changes drastically, by up to five orders of magnitude, with varying deposition temperature from $90^{\circ} \mathrm{C}$ to $210^{\circ} \mathrm{C}$. However, there is no direct simple dependency of the layer resistivity on the film's composition. Presumably, the high inclusion of residues from precursor leads to high resistivity. However, low residue concentrations do not necessarily lead to low resistivity.

\section{ACKNOWLEDGMENTS}

The work of G. Chistiakova, M. Mews and L. Korte was supported by the German Federal Ministry for Economic Affairs and Energy within the research cluster "Persist" under Grant 0324037C. R.G. Wilks, and M. Bär additionally acknowledge funding from the Helmholtz Association (VH-NG- 423). The authors would like to thank Kerstin Jacob, Mona Wittig, Florian Ruske and Martin Reiche for experimental and technical support.

${ }^{1}$ J. Huang, N. Matsunaga, K. Shimanoe, N. Yamazoe, and T. Kunitake, Chem. Mater. 17, $3513(2005)$.

${ }^{2}$ P. Meduri, C. Pendyala, V. Kumar, G.U. Sumanasekera, and M.K. Sunkara, Nano Lett. 9, 612 (2009).

${ }^{3}$ L. Zheng, Y. Zheng, C. Chen, Y. Zhan, X. Lin, Q. Zheng, K. Wei, and J. Zhu, Inorg. Chem. 48, 1819 (2009).

${ }^{4}$ S. Trost, K. Zilberberg, A. Behrendt, and T. Riedl, J. Mater. Chem. 22, 16224 (2012).

${ }^{5}$ Z.C. Holman, a. Descoeudres, L. Barraud, F.Z. Fernandez, J.P. Seif, S. De Wolf, and C. Ballif, IEEE J. Photovoltaics 2, 7 (2012).

${ }^{6}$ C. Zhang, M. Meier, A. Hoffmann, W. Zhang, K. Bittkau, G. Jost, U.W. Paetzold, M. Ermes, and T. Merdzhanova, IEEE J. Photovoltaics 5, 33 (2015).

${ }^{7}$ J.R. Bakke, K.L. Pickrahn, T.P. Brennan, and S.F. Bent, Nanoscale 3, 3482 (2011).

${ }^{8}$ J.P. Correa Baena, L. Steier, W. Tress, M. Saliba, S. Neutzner, T. Matsui, F. Giordano, T.J. Jacobsson, A.R. Srimath Kandada, S.M. Zakeeruddin, A. Petrozza, A. Abate, M.K. Nazeeruddin, M. Grätzel, and A. Hagfeldt, Energy Environ. Sci. 8, 2928 (2015).

${ }^{9}$ Y. Lee, S. Paek, K.T. Cho, E. Oveisi, P. Gao, S. Lee, J.-S. Park, Y. Zhang, R. HumphryBaker, A.M. Asiri, and M.K. Nazeeruddin, J. Mater. Chem. A 5, 12729 (2017). 
${ }^{10}$ T. Hu, T. Becker, N. Pourdavoud, J. Zhao, K.O. Brinkmann, R. Heiderhoff, T. Gahlmann, Z. Huang, S. Olthof, K. Meerholz, D. Többens, B. Cheng, Y. Chen, and T. Riedl, Adv. Mater. 29, 1606656 (2017).

${ }^{11}$ C. Wang, D. Zhao, C.R. Grice, W. Liao, Y. Yu, A. Cimaroli, N. Shrestha, P.J. Roland, J. Chen, Z. Yu, P. Liu, N. Cheng, R.J. Ellingson, X. Zhao, and Y. Yan, J. Mater. Chem. A 4, 12080 (2016).

${ }^{12}$ K. a. Bush, A.F. Palmstrom, Z.J. Yu, M. Boccard, R. Cheacharoen, J.P. Mailoa, D.P. McMeekin, R.L.Z. Hoye, C.D. Bailie, T. Leijtens, I.M. Peters, M.C. Minichetti, N. Rolston, R. Prasanna, S. Sofia, D. Harwood, W. Ma, F. Moghadam, H.J. Snaith, T. Buonassisi, Z.C. Holman, S.F. Bent, and M.D. McGehee, Nat. Energy 2, 17009 (2017).

${ }^{13}$ S. Albrecht, M. Saliba, J.P. Correa Baena, F. Lang, L. Kegelmann, M. Mews, L. Steier, A. Abate, J. Rappich, L. Korte, R. Schlatmann, M.K. Nazeeruddin, A. Hagfeldt, M. Grätzel, and B. Rech, Energy Environ. Sci. 9, 81 (2016).

${ }^{14}$ J.W. a Schüttauf, C.H.M. Van Der Werf, I.M. Kielen, W.G.J.H.M. Van Sark, J.K. Rath, and R.E.I. Schropp, J. Non. Cryst. Solids 358, 2245 (2012).

${ }^{15}$ D. V. Nazarov, M.Y. Maximov, P.A. Novikov, A.A. Popovich, A.O. Silin, V.M. Smirnov, N.P. Bobrysheva, O.M. Osmolovskaya, M.G. Osmolovsky, and A.M. Rumyantsev, J. Vac.

Sci. Technol. A Vacuum, Surfaces, Film. 35, 01B137 (2017).

${ }^{16}$ B. Macco, M.F.J. Vos, N.F.W. Thissen, A.A. Bol, and W.M.M. Kessels, Phys. Status Solidi - Rapid Res. Lett. 9, 393 (2015).

${ }^{17}$ B. Demaurex, S. De Wolf, A. Descoeudres, Z. Charles Holman, and C. Ballif, Appl. Phys. Lett. 101, 171604 (2012).

${ }^{18}$ H.B. Profijt, P. Kudlacek, M.C.M. van de Sanden, and W.M.M. Kessels, J. Electrochem. Soc. 158, G88 (2011).

${ }^{19}$ J.W. Elam, D. a. Baker, A.J. Hryn, A.B.F. Martinson, M.J. Pellin, and J.T. Hupp, J. Vac. Sci. Technol. A Vacuum, Surfaces, Film. 26, 244 (2008).

${ }^{20}$ D.W. Choi and J.S. Park, Surf. Coatings Technol. 259, 238 (2014).

${ }^{21}$ W. Kern and J.E. Soc, J. Electrochem. Soc. 137, 1887 (1990).

22 J.L. Van Hemmen, S.B.S. Heil, J.H. Klootwijk, F. Roozeboom, C.J. Hodson, M.C.M. Van De Sanden, and W.M.M. Kessels, J. Electrochem. Soc. 154, G165 (2007).

${ }^{23}$ H.B. Profijt, S.E. Potts, M.C.M. van de Sanden, and W.M.M. Kessels, J. Vac. Sci. Technol. A Vacuum, Surfaces, Film. 29, 050801 (2011).

${ }^{24}$ K.E. Elers, T. Blomberg, M. Peussa, B. Aitchison, S. Haukka, and S. Marcus, Chem. Vap. Depos. 12, 13 (2006).

${ }^{25}$ M. Wojdyr, J. Appl. Crystallogr. 43, 1126 (2010). 
${ }^{26}$ G. Abowitz and E. Arnold, Rev. Sci. Instrum. 38, 564 (1967).

${ }^{27}$ M.N. Mullings, C. Hägglund, J.T. Tanskanen, Y. Yee, S. Geyer, and S.F. Bent, Thin Solid Films 556, 186 (2014).

${ }^{28}$ J.J. Chance and W.C. Purdy, Langmuir 7463, 4487 (1997).

${ }^{29}$ E.L. Bruner, A.R. Span, S.L. Bernasek, and J. Schwartz, Langmuir 17, 5696 (2001).

${ }^{30}$ D. Choi, W.J. Maeng, and J.-S. Park, Appl. Surf. Sci. 313, 585 (2014).

${ }^{31}$ M.N. Mullings, C. Hägglund, and S.F. Bent, J. Vac. Sci. Technol. A Vacuum, Surfaces, Film. 31, 061503 (2013).

${ }^{32}$ E. Shanthi, A. Banerjee, and K.L. Chopra, Thin Solid Films 88, 93 (1982).

${ }^{33}$ T.F. Schulze, L. Korte, F. Ruske, and B. Rech, Phys. Rev. B - Condens. Matter Mater. Phys. 83, (2011).

${ }^{34}$ X. Cao, L. Cao, W. Yao, and X. Ye, Thin Solid Films 317, 443 (1998).

${ }^{35}$ S. Franke, M. Baumkötter, C. Monka, S. Raabe, R. Caspary, H.-H. Johannes, W.

Kowalsky, S. Beck, A. Pucci, and H. Gargouri, J. Vac. Sci. Technol. A Vacuum, Surfaces, Film. 35, 01B117 (2017).

${ }^{36}$ W.-K. Choi, H.-J. Jung, and S.-K. Koh, J. Vac. Sci. Technol. A Vacuum, Surfaces, Film. 14, 359 (1996).

${ }^{37}$ R. Matero, a Rahtu, M. Ritala, M. Leskelä, and T. Sajavaara, Thin Solid Films 368, 1 (2000).

${ }^{38}$ E. Langereis, J. Keijmel, M.C.M. Van De Sanden, and W.M.M. Kessels, Cit. Appl. Phys. Lett. 921, 231904 (2008). 